Bayesian Analysis and

Uncertainty in

Economic Theory 


\title{
BAYESIAN ANALYSIS AND UNCERTAINTY IN ECONOMIC THEORY
}

\author{
RICHARD M. CYERT \\ MORRIS H. DeGROOT
}

Carnegie Mellon University 
First published 1987 by

Chapman and Hall Limited

11 New Fetter Lane, London EC4P 4EE

Copyright (C) 1987

Softcover reprint of the hardcover lst edition 1987

Richard M. Cyert and Morris H. DeGroot

ISBN-13: 978-94-010-7922-8

e-ISBN-13: 978-94-009-3163-3

DOI: $10.1007 / 978-94-009-3163-3$

All rights reserved 
To our wives,

Margaret S. Cyert and Marilyn D. DeGroot, whose indifference to this work was deeply appreciated by us. 


\section{Contents}

Preface ix

Acknowledgments xiii

1 Introduction 1

2 Bayesian Decision Theory 7

3 Behavioral and Control Theory of the Firm 27

4 Bayesian Analysis and Duopoly Theory 41

5 Multiperiod Decision Models with Alternating Choice as a Solution to the Duopoly Problem 57

6 Cooperation and Learning in a Duopoly Context 74

7 Interfirm Learning and the Kinked Demand Curve 93

8 Sequential Strategies in Dual Control Problems 109

9 Adaptive Utility 127

10 Some Examples of Adaptive Utility 144

11 Sequential Investment Decisions 152

12 Capital Allocation within Firms 162

13 Rational Expectations 171

14 Epilogue 186

$\begin{array}{ll}\text { References } & 189\end{array}$

Author Index 199

Subject Index 203 


\section{Preface}

We began this research with the objective of applying Bayesian methods of analysis to various aspects of economic theory. We were attracted to the Bayesian approach because it seemed the best analytic framework available for dealing with decision making under uncertainty, and the research presented in this book has only served to strengthen our belief in the appropriateness and usefulness of this methodology. More specifically, we believe that the concept of organizational learning is fundamental to decision making under uncertainty in economics and that the Bayesian framework is the most appropriate for developing that concept.

The central and unifying theme of this book is decision making under uncertainty in microeconomic theory. Our fundamental aim is to explore the ways in which firms and households make decisions and to develop models that have a strong empirical connection. Thus, we have attempted to contribute to economic theory by formalizing models of the actual process of decision making under uncertainty. Bayesian methodology provides the appropriate vehicle for this formalization.

We recognize that the topic of decision making under uncertainty is a wide one, and one that is actively being studied from many different perspectives. In particular, we applaud the work done by many economists in attempting to model oligopolies through the use of supergames and games of incomplete information. We are concerned, however, that the expectational assumptions of game theory, including dynamic "supergames" with imperfect information, have a weak empirical basis. The ongoing development of game theory through the use of more sophisticated mathematical models, we believe, is at best tangential to the actual process of decision making under uncertainty. Hence, we have largely eschewed this topic and its literature in favor of the Bayesian approach that is more relevant to our objective.

Advocates of game theory may still wonder why we have not emphasized Bayesian game theory. From our perspective, Bayesian game theory 
refers to models and processes in which the firms or other decision makers represent their uncertainties about their rivals and other aspects of their environment by their actual subjective probability distributions, unconstrained by any ad hoc expectational or equilibrium assumptions. In the framework of this definition, as described in Chapter 2, Bayesian game theory is clearly in an incipient stage. It is a promising but as yet undeveloped methodology.

The use of subjective probability in decision making under uncertainty is still relatively uncommon and not well understood in economics. One obvious confirmation of this assertion is the popularity of rational-expectations models, which enable economists to construct dynamic models in which there is a well-defined formula for the expectations to be used. Some type of expectation lies at the base of every dynamic model in economics, and the rational-expectations approach eases the problem of the specification of expectations, despite the typical lack of any empirical justification. Although we show in Chapter 13 that our approach can be used in some contexts to develop a process by which the rational-expectations equilibrium is attained, it is more often true that our approach is to be contrasted with rational expectations. We have utilized a decisionmaking process that we think has empirical validity. Therein, for us, lies the beauty of the work and its potential usefulness.

Because this book has evolved from a series of articles, we are sensitive (perhaps even defensive) about its cohesiveness. We have rewritten large segments of a number of the articles and, in particular, have developed a unified notation. In addition, new material has been included throughout the book.

Because our central and pervasive topic is decision making under uncertainty, we have included our work on adaptive utility. In adaptive utility models, firms and consumers must learn about and refine their own tastes and preferences, as well as learn about their environment, by making decisions under uncertainty and evaluating their experiences. We think the concept of adaptive utility has empirical relevance and great potential for theory. We have emphasized the cohesiveness of all our material by liberal cross-referencing throughout the book. It may be true that a few chapters are expendable in the sense that our points could be made even if they were omitted, but each chapter adds something new and the chapters are all connected by our general theme.

It is impossible to list the names of colleagues to whom we are indebted because the list is so extensive. We have received a large number of comments over the years that have resulted in improvements of our work, and this book incorporates those comments.

We are pleased with the great increase of activity in the area of Bayesian analysis applied to economic theory since we first published on this 
topic. We believe, however, that much remains to be done in this area. Our hopes for this book are that it will prove to be the stimulus that induces additional work and that it will make a contribution to economics and statistics, two fields about which we both care.

Richard M. Cyert

Morris H. DeGroot

Carnegie Mellon University

Pittsburgh, Pennsylvania

January 1987 


\section{Acknowledgments}

We owe a significant debt to our colleague Herbert A. Simon, to the late Leonard J. Savage, and to George J. Stigler, all of whom have influenced us at various times in our lives. None of them would agree with everything in the book, but we hope there are some parts that reflect their influence.

The continuous support of the National Science Foundation over the life of this research is deeply appreciated.

We thank Charles A. Holt for permitting us to adapt material from the articles of which he was a coauthor.

We also thank the publishers of the following articles for permission to adapt portions of them in this book:

"Bayesian analysis and duopoly theory," Journal of Political Economy 78 (1970). Reprinted with revisions in Studies in Bayesian Econometrics and Statistics, ed. S. E. Fienberg and A. Zellner. North-Holland Publishing Co. (1975).

"Multiperiod decision models with alternating choice as a solution to the duopoly problem," Quarterly Journal of Economics 84 (1970).

"Interfirm learning and the kinked demand curve," Journal of Economic Theory 3 (1971).

"An analysis of cooperation and learning in a duopoly context," American Economic Review 63 (1973).

"Rational expectations and Bayesian analysis," Journal of Political Economy 82 (1974).

"Adaptive utility," Adaptive Economic Models, ed. R. H. Day and T. Groves. Academic Press (1975). Reprinted in Expected Utility and the Allais Paradox, ed. M. Allais and O. Hagen. D. Reidel Publishing Co. (1979).

"Sequential strategies in dual control problems," Theory and Decision 8 (1977). 
Bayesian Analysis and

Uncertainty in Economic Theory 